\title{
The Role of Building Codes and Controls in Enhancing Community Resilience
}

\author{
Sheila J. Hayter ${ }^{1, *}$ and Sherry Stout ${ }^{2}$ \\ ${ }^{1}$ ASHRAE, 2018-2019 President, 1791 Tullie Circle Northeast, Atlanta, Georgia, USA www.ashrae.org \\ ${ }^{2}$ National Renewable Energy Laboratory, Integrated Applications Center, 15013 Denver West Parkway, Golden, Colorado, USA \\ www.nrel.gov
}

\begin{abstract}
Countries, states, and cities around the world are seeking to enhance power sector resilience through a combination of policy and technology. However, few of these efforts fully incorporate the built environment into power sector planning. Buildings account for more than a third of the global annual energy consumption and more than $60 \%$ of the annual electricity consumption. As such, buildings play a critical role in enhancing resilience in the power sector. Buildings can aid in power sector resilience by increasing power system flexibility, shaving and shifting demand, and providing on-site energy generation. All of these strategies require incentives to encourage participation. This paper presents an overview of energy management strategies to better incorporate building design and operation in power sector resilience planning.
\end{abstract}

\section{Background}

\subsection{Building Energy Use}

Worldwide, buildings annually account for nearly $40 \%$ of final energy use[1] and more than $60 \%$ of electricity use[2] While the average energy intensity of buildings is expected to decrease [3] the total number of buildings and thus total energy consumption - will continue to increase [4] Worldwide, that growth rate is even more substantial -with urbanization resulting in construction of building stock equivalent to a city the size of Singapore every month until 2050 [5].

This rapid growth creates new strains on the electrical grid. This strain is particularly acute during times of peak demand and during extreme weather events such as storms, heatwaves, and cold snaps. In some cases, these events precipitate into blackouts or brownouts as generation seeks to keep up with demand. As extreme events including, heatwaves, polar vortices, and floods become more common and less predictable, the need for greater power sector resilience becomes more and more apparent.

\subsection{Power Sector Resilience}

Resilience is the ability to anticipate, prepare for, and adapt to changing conditions and withstand, respond to, and recover rapidly from disruptions through adaptable and holistic planning and technical solutions.[6] Power sector vulnerabilities can be exposed by a variety of threats including natural hazards, technological hazards, and human caused accidents. The combination of vulnerability and exposure creates risk for the power sector. As buildings represent the largest end-use of electricity, they can represent significant risk to the power sector if not designed and managed for resilience. However, buildings can also represent a resilience resource for the power sector when incentivized to do so.

The 2017 Staff Report to the Secretary on Electricity Markets and Reliability by the U.S. Department of Energy noted that adoption of energy efficiency programs, demand response programs, transmission capacity increases, and microgrids with energy storage enhance electric system flexibility, reliability, and resilience [7]. While three out of four of these programs can relate directly to building systems, none are mandated in U.S. national building policy or regulatory frameworks. This paper explores ways in which the building sector can aid in enhancing resilience through smart design and control of building energy loads and participation in energy system planning and operation.

\section{Building Efficiency Codes and Benchmarking}

The first step in incorporating building design into resilient power systems is to reduce the energy intensity of the local building stock. This is most often accomplished through energy efficiency measures. Adoption of national building energy codes has been slow with only 69 countries having some form of national voluntary or mandatory building energy codes (figure 1).

\footnotetext{
*orresponding author: author@e-mail.org
} 


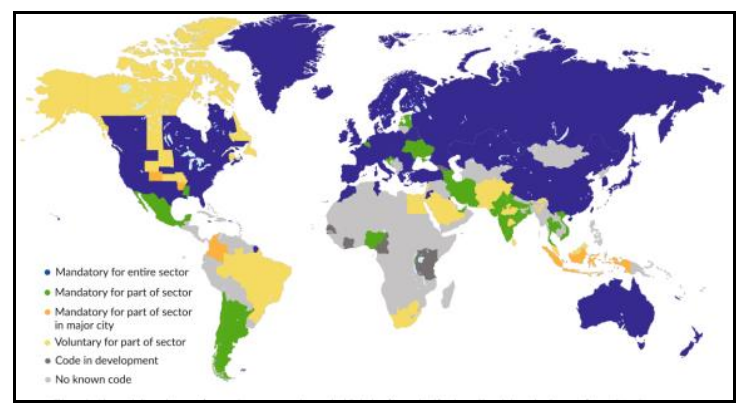

Figure 1: Energy Code Adoption by Jurisdiction[8]

The U.S. does not currently have a national building energy code [9]. However, most states employ energy efficiency codes related either to ASHRAE 90.1 or one of the IECC iterations [10]. Only10 states lack mandatory statewide energy codes that meet at least the 2009 IEC standards for new residential and/or commercial buildings [11]. Internationally, the trend in sub-national action on building energy is equally apparent - with 19 cities representing 130 million people committed to achieve net-zero carbon in new construction by 2030.[12]

\subsection{Building Energy Benchmarking}

The U.S. DOE defines energy benchmarking as "a market-based policy tool to increase building energy performance awareness among key stakeholders and create demand for energy efficiency improvements [13]." The Institute for Market Research's BuildingRatings.org tracker shows that at least 55 U.S. jurisdictions have adopted energy performance benchmarking or disclosure policies (figure 2).

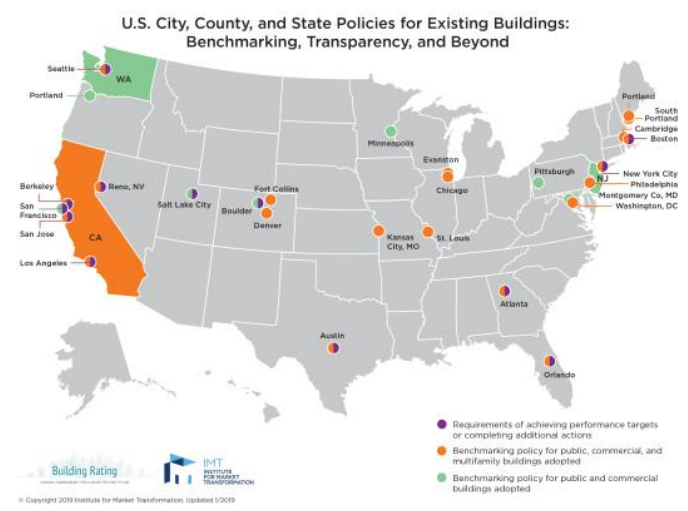

Figure 2: Energy benchmarking by location in the U.S. [14]

These policies vary widely in the types of building required to comply, level of energy data transparency, and types of enforcement mechanisms. The ultimate goal of these programs is to collect data on building energy consumption to spur action - whether policy or human behavior - that increases energy efficiency in the built environment. For example, the City of Seattle publishes energy benchmark data on non-residential and multifamily in an interactive map (figure 7) with the goal of increasing the market value of energy efficiency. The map allows potential renters or buyers to compare longterm costs of operating a building and aids the city in tracking progress toward energy and carbon reduction goals. Energy benchmarking also shows building operators how they are using energy and aids them in understanding implications of various energy saving measures.

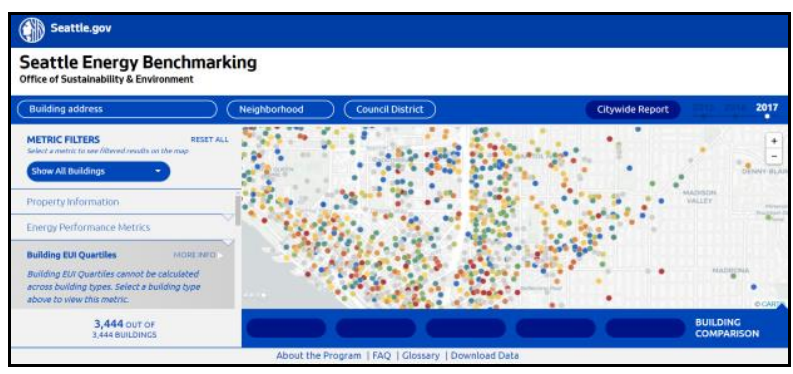

Figure 3: Seattle Energy Benchmarking Public Disclosure Site [15].

\section{Building Participation in Energy Planning}

Understanding energy use and reducing total building energy loads will aid in increasing power system flexibility but will not fully solve resilience challenges. Building operators need to use that data become responsive to utility and customer needs. This can be accomplished through a variety of programs and technologies including innovative rate design and price signals, demand response, and on-site power generation.

Historically, the flow of electrons and information has been unidirectional - flowing from utility to load. Utilities have employed relatively low, flat rate structures - particularly for residential customers and have had relatively little insight into real-time customer load behavior [16]. Additionally, energy consumption has typically been aggregated to a monthly bill which allows limited visibility into behaviors and consumption practices over the course of the billing period. This has restricted the ability of both the customer and utility to understand how and when energy was consumed. However, over the past decades, advances in distributed energy resources (DER), smart control systems, and advanced metering infrastructure (AMI) have allowed the electrical load to talk back to the utility. Meters now allow remote access to time-of-day data and near-real time power generation information from on-site DER.

These technological advances are also changing how utilities manage power. Better rate design has been employed to allow for reduced kilowatt-hour (kWh) sales without reducing utility revenue while also reducing strain on grid resources during times of peak demand. The American Council for an Energy-Efficient Economy (ACEEE) notes that rate structures that encourage energy efficiency and reduce peak demand specifically include time-of-use (TOU) rates, peak-time rebates (PTR), and critical-peak pricing (CPP) [17]. Lazar and Gonzalez report that "[r]ate design is 
important because the structure of prices - that is, the form and periodicity of prices for the various services offered by a regulated company - has a profound impact on the choices made by customers, utilities, and other electric market participants [18]."

\subsection{Building Interaction with Rate Structures}

The proliferation of "smart" technologies is now allowing greater insight into, and control of, energy use in buildings than ever before. At the residential level, energy customers can automate lights, appliances, thermostats, and more to maximize comfort levels, efficiency, and cost savings with utility rates. At the commercial scale, opportunities for automation are even greater. Buildings can integrate refrigeration, HVAC, lighting, mission-critical systems, and watering systems in to energy management energy management platforms that can optimize building performance to multiple criteria ranging from utility cost optimization to occupant comfort.

\subsection{Demand Response}

The next level of building interaction with utility rates and price signals is Demand Response (DR). DR enables building to directly participate in the management of the power system while benefiting both the building operator and overall grid. The building operator maximizes energy cost savings while the grid operator reduces strain on resources during times of high demand.

Rising temperatures and extreme heat events drive demand for increased cooling. In the U.S., rising temperatures and extreme events are predicted to increase energy demand by $4-18 \%$ by 2040 [19]. At the same time, these rising temperatures may simultaneously result in reduced generation and transmission capacity and efficiency. This combination of increased demand and reduction of load can strain power grids and lead to brownouts - or temporary reduction in power provided to end users.

Demand response allows the electric utility to more easily balance supply and demand through a variety of programs that aim to change the timing of energy use through customer incentives. By implementing demand response programs, utilities may be able to avoid implementing brownouts to reduce system strain. Gagne et al. noted that successful programs have the following attributes:

- Low barriers to entry for potential participants,

- A compensation methodology that encourages participation,

- Confidence that there is sufficient reliable demand response during peak hours to avoid building new capacity. [20]

In the U.S., building operators participating in demand response programs are generally guaranteed compensation for their demand reduction contributions to the market. Cui et al. notes that "From the building perspective, this means that smart buildings with demand response capability are able to participate in the wholesale electricity markets by providing demand response energy reductions, and they will be compensated as if they were generating electricity [21]."

There are essentially two types of demand response: dispatchable and non-dispatchable [22] Nondispatchable demand response is typically voluntary and therefore generally harder to predict for system operators. Dispatchable demand response - also known as automated demand response - is mandatory and generally controlled by the system operator based on contractual agreements with the customer. Samad et al. explains automated demand response as "implementation in which the signal is received by control equipment at the customer's facility such that preprogrammed DR strategies are enacted in an automated fashion without human intervention [23]." As such, building automation plays a key role in allowing demand response programs to add needed flexibility to power generation, transmission, and distribution. Two-way communication between the grid operator and building controls relay real-time energy use and load reduction signals. Hale et al. reports that "On the commercial and industrial side, automated control and metrology is generally required for modern demand response programs" whereas "Automated demand response programs in the residential sector typically take the form of direct load control of appliances such as air conditioners and water heaters. More recently, aggregations of programmable controlled thermostats have been added to the mix [24]."

\section{On-Site Generation and Microgrids}

As building operators seek to become more resilient, many look to on-site electricity generation and microgrids to reduce energy costs and provide continuity of operations in the event of power outages.

On-site power generation most often is in the form of solar photovoltaics (PV) but can also include small scale wind turbines, biomass combined heat and power, and fuel-based generators. These systems are generally designed to offset power use - either at specific times or on an average-use basis. On-site generation may be able to reduce the overall energy load of a building or campus and therefore reduce total energy costs. However, without coupled storage, on-site generation has limited ability to participate in peak shifting or demand response as generation can be unpredictable on an intra-day basis.

Microgrids, on the other hand, are systems of interconnected loads and DER systems that can operate while connected to the grid or when separated from the grid (referred to as being islanded). When connected to the grid, building or campus energy managers can use microgrids for demand response, peak shaving, and/or load shifting to reduce energy costs. When islanded, microgrids have the capability of producing and distributing power apart from the grid.

One such example of microgrid power during an emergency situation can be found at Princeton University in New Jersey. During the power outages that 
left over eight million Americans in the dark, [25] Princeton University provided power and a base of operations for emergency management teams through an innovative campus microgrid. Princeton University's microgrid - a hybrid of natural gas combined heat and power and solar PV - was able to island from the damaged grid in order to provide power to critical campus facilities [26].

\section{Conclusion}

Electric power is the cornerstone of nearly all modern activity. From banking and commerce to healthcare and water treatment, modern societies are dependent on reliable, affordable power. Changing climates can affect electricity supply (through changing generation profiles and efficiency of transmission) and demand (by altering heating and cooling needs). Additionally, as extreme events increase in both frequency and severity, power outages become more frequent and longer-lasting [27]. As such, countries, states, and cities around the world are seeking to enhance resilience of their electric power systems to ensure safety and economic prosperity for their populations. While many jurisdictions and utilities are incorporating new and more robust technologies into grid networks, few are truly considering the role of buildings in increasing electric power resilience.

As the largest share of worldwide electricity use, buildings can play a key role in enhancing resilience of the electric power system. Buildings can play and important role in increasing power system flexibility through load reduction, demand response, and on-site energy generation. However, building operators and occupants often only incorporate these tactics when incentivized to do so. These incentives can be in the form of rewards - such as financial compensation for automated demand response or on-site energy generation - or in the form of mandates - such as required energy benchmarking and public disclosure of building energy use. In either case, power sector planners and operators must better incorporate building design and energy elasticity into their generation and load planning. Building operators likewise must participate in power sector operations by implementing innovative solutions to maximize resilience while still meeting occupant comfort and usability needs.

Building codes are the minimum legal requirement to which construction must comply - and these rarely include provisions for extreme events or energy management. Existing energy standards, such as ASHRAE 90.1 and 90.2 that are referenced in building codes, could be bolstered to include resilience provisions such as the ability to shift load during extreme events. Enhancing building codes for extreme events and energy management - and designing new and creative ways to incentivize and enforce them - is key to enhancing resilience in the power sector and in the building environment.

\section{References}

1. P Graham. Global Alliance on Buildings and Construction, UN Environment (2018)

2. Building Our New Energy Future: What Buildings Professionals Need to Know About Changes Coming to the Electricity Sector," ASHRAE (2018)

3. EIA Annual Energy Outlook (2019)

4. Ibid.

5. Building Our New Energy Future: What Buildings Professionals Need to Know About Changes Coming to the Electricity Sector," ASHRAE (2018)

6. Resilience Roadmap. NREL, (2018)

7. Staff Report to the Secretary on Electricity Markets and Reliability. U.S. DOE, (2018)

8. P Graham. Global Alliance on Buildings and Construction, UN Environment (2018)

9. EIA Annual Energy Outlook (2019)

10. B. Baatz, Rate Design Matters: The Intersection of Residential Rate Design and Energy Efficiency, ACEEE, (2017)

11. Adoption Process State Technical Assistance Status of State Energy Code Adoption Compliance Resource Center Status of State Energy Code Adoption," U.S. DOE, (2019)

12. P Graham. Global Alliance on Buildings and Construction, UN Environment (2018)

13. State and Local Energy Benchmarking and Disclosure Policy," U.S. DOE, (2019)

14. U.S. City, County, and State Policies for Existing Buildings: Benchmarking, Transparency and Beyond, Institute for Market Research (2019)

15. Seattle Energy Benchmarking, City of Seattle (2019)

16. J. Lazar, W Gonzalez, Smart Rate Design for a Smart Future, RAP (2015)

17. B. Baatz, Rate Design Matters: The Intersection of Residential Rate Design and Energy Efficiency, ACEEE, (2017)

18. J. Lazar, W Gonzalez, Smart Rate Design for a Smart Future, RAP (2015)

19. K. Larsen, J. Larsen, M. Delgado, Whitney Herndon, S Mohan, Assessing the Effect of Rising Temperatures: The Cost of Climate Change to the U.S. Power Sector, Rhodium Group, (2017)

20. D. Gagne, E. Settle, A. Aznar, R. Bracho. "Demand Response

Compensation 
Methodologies: Case Studies for Mexico," NREL (2018)

21. T. Cui, J. Carr, A Brissette, E. Ragaini, 8th International Conference on Sustainability in Energy and Buildings, (2016)

22. D. Gagne, E. Settle, A. Aznar, R. Bracho. "Demand Response Compensation Methodologies: Case Studies for Mexico," NREL (2018)

23. T. Samad, E. Koch, P. Stluka, IEEE 104, (2016)
24. E. Hale, L. Bird, R. Radmanabhan, C. Volpi Potential Roles for Demand Response in HighGrowth Electric Systems with Increasing Shares of Renewable Generation, NREL (2018)

25. H. Devanandham, J. Emmanuel Ramirez-Marquez, Systems Engineering, 19, 59-75, (2016)

26. M. Kelly, Princeton University, (2014)

27. Climate Change and the U.S. Energy Sector: Regional Vulnerabilities and Resilience Solutions. U.S. DOE, (2015) 